\title{
Prevalence and factors associated with scleral hyaline plaque: clinical study of older adults in southeastern Brazil
}

This article was published in the following Dove Press journal:

Clinical Ophthalmology

30 June 2015

Number of times this article has been viewed

\author{
Soraya Horowitz' \\ Nadyr Damasceno' \\ Eduardo Damasceno ${ }^{2}$ \\ 'Department of Ophthalmology, \\ Hospital Naval Marcilio Dias, \\ Rio de Janeiro, ${ }^{2}$ Department of \\ Ophthalmology, Universidade Federal \\ Fluminense, Niterói, Brazil
}

Purpose: To investigate the prevalence of scleral hyaline plaque among older adults in the city of Niterói in southeastern Brazil. A second goal was to assess the correlation between scleral hyaline plaque and several age-related diseases, including eye diseases and systemic diseases.

Methods: The study sample comprised 667 participants who were followed for 15 months. The study had a prospective, longitudinal, observational design that established inclusion and exclusion criteria. The following variables were selected for correlation with scleral hyaline plaque: sex, age, age range, iris color, ethnicity, presence of cataract, moderate to high myopia, age-related macular degeneration (AMD), diabetes mellitus, systemic arterial hypertension, degenerative arthritis, and osteoporosis. These correlations were assessed by means of the $\chi^{2}$ test and Student's $t$-test. Multivariate analysis was performed to exclude factors that were potentially associated with aging exclusively but that did not have a direct relationship with hyaline plaque. Binary logistic regression was used to calculate odds ratios, significance, and confidence intervals.

Results: Scleral hyaline plaques were found in 177 patients $(17.54 \%)$. There was a statistically significant association between the presence of hyaline plaques and sex (female), age range ( $\geq 70$ years old), ethnicity (Caucasian), cataract, moderate to high myopia, systemic arterial hypertension, degenerative arthritis, and osteoporosis $(P<0.05)$. On multivariate binary logistic regression analysis, only female sex, age range ( $\geq 70$ years), moderate to high myopia, and degenerative arthritis exhibited significant correlation.

Conclusion: The prevalence of scleral hyaline plaque in the present study was higher than in previous reports in the medical literature. Several age-related diseases exhibited a correlation with scleral hyaline plaque. The most significant factors associated with scleral hyaline plaque were advanced age, female sex, moderate to high myopia, and degenerative arthritis.

Keywords: age-related eye diseases, age-related systemic diseases, factors associated with age-related disorders

\section{Introduction}

Scleral hyaline plaque is a result of an age-related hyaline degeneration of the sclera and is usually asymptomatic. The scleral area affected becomes thin and slightly depressed. The lesions are described as bilateral, symmetric, well-defined, and with a vertically ovoid shape. Sometimes lesions appear as rectangular areas of increased scleral translucency. ${ }^{1-4}$ They are usually located before the insertion of the medial and lateral rectus muscles, and possibly cause calcification, turning translucent, and thus obtaining a whitish color. ${ }^{2,4-6}$

Many of the articles published on scleral plaque were written 30-50 years ago. Some authors consider scleral hyaline plaque as a minor degenerative condition, due to its asymptomatic nature. Some patients may exhibit specific characteristics like
Correspondence: Eduardo Damasceno Department of Ophthalmology, Marques do Paraná 303 Niteroi, 20530050, Brazil Email e_damasceno@yahoo.com 
calcification and its radiological images. ${ }^{7-9}$ The purpose of this present study was to assess the prevalence of scleral hyaline plaque and identify factors and comorbidities associated with its onset.

\section{Methods}

The study population comprised 667 individuals who underwent ophthalmological consultations at a university hospital. With respect to study design, the present study was a prospective, longitudinal, observational study.

The study complied with the Norms and Considerations for Human Research (National Health Council Resolution 196/1996 Ref: CAAE:01111312900005243) and was approved by The Research Ethics Committee of The School of Medicine. All the participants signed informed consent form. Inclusion and exclusion criteria were established to obtain a homogeneous sample.

All patients older than 50 years old who underwent an ophthalmological consultation at Antonio Pedro University Hospital in Niterói in southeastern Brazil were subjected to the inclusion criteria. The study was conducted from January 2013 to April 2014, resulting in the initial inclusion of 2,000 patients. Medical consultations were scheduled at 6-month intervals in each case.

The exclusion criteria included all conditions liable to affect the ocular surface, such as prolonged use of eye drops (ocular lubricants, topical steroids, and antiglaucoma agents), chronic use of systemic corticosteroids, previous intraocular surgery, glaucoma, rheumatic diseases (systemic lupus erythematosus, rheumatoid arthritis, and scleroderma), scleritis, uveitis, a history of ocular trauma, and pterygium and other conjunctival degenerations. The application of the inclusion and exclusion criteria resulted in a sample of 667 participants. In most cases, exclusion was due to cataract surgery or the use of ocular lubricants for dry eye treatment.

Personal epidemiological data (sex, ethnicity, age, and iris color) as well as information on the participants' past clinical history and medications used were collected for the study. All of the participants underwent an ophthalmological examination, which included the following components: best-corrected visual acuity, assessed using the Snellen chart; intraocular pressure, measured with a Goldmann tonometer; indirect ophthalmoscopy (Welch Allyn, Inc. Skaneateles Falls, NY, USA); and slit lamp biomicroscopy of the anterior segment. Slit lamp biomicroscopy allowed the analysis of the scleral hyaline plaques and their classification as the complete or incomplete form according to their size and aspect of the scleral surface. Bilateral and symmetric plaques as well as lesions measuring more than $2 \mathrm{~mm}$ (Figure 1) were classified

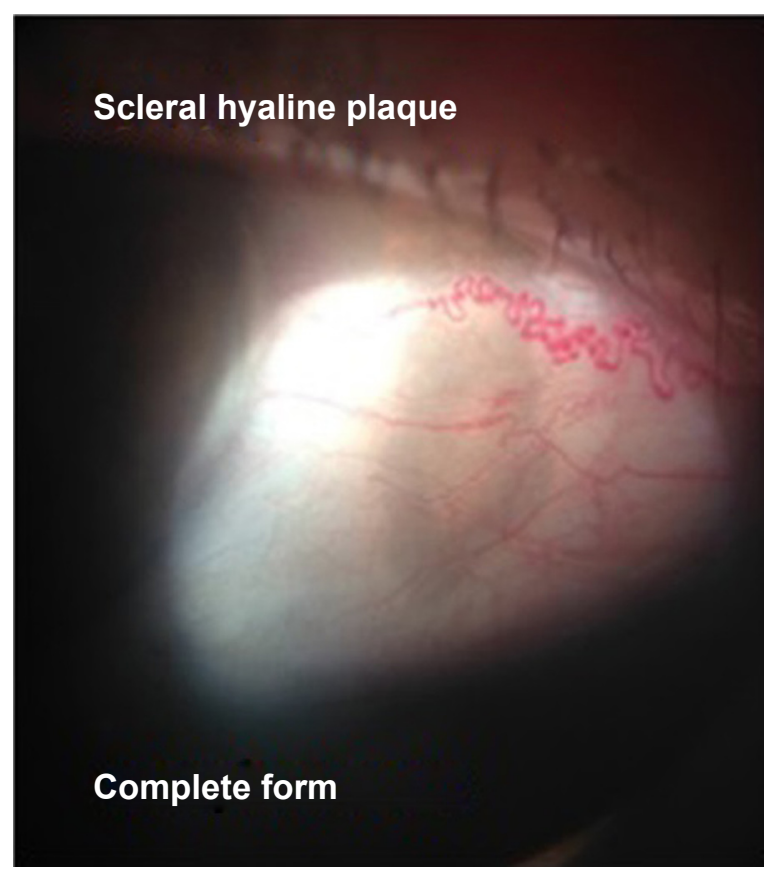

Figure I Biomicroscopy of anterior segment. Scleral hyaline plaque - Complete form.

as complete plaques. However, bilateral but asymmetric plaques and lesions measuring less than $2 \mathrm{~mm}$ were considered incomplete (Figure 2). The evolution of the plaques (increase in size) was assessed during the follow up.

\section{Investigated variables}

\section{Scleral hyaline plaque}

The plaque (complete or incomplete) could be considered as present or absent. In addition, characteristics such as plaque

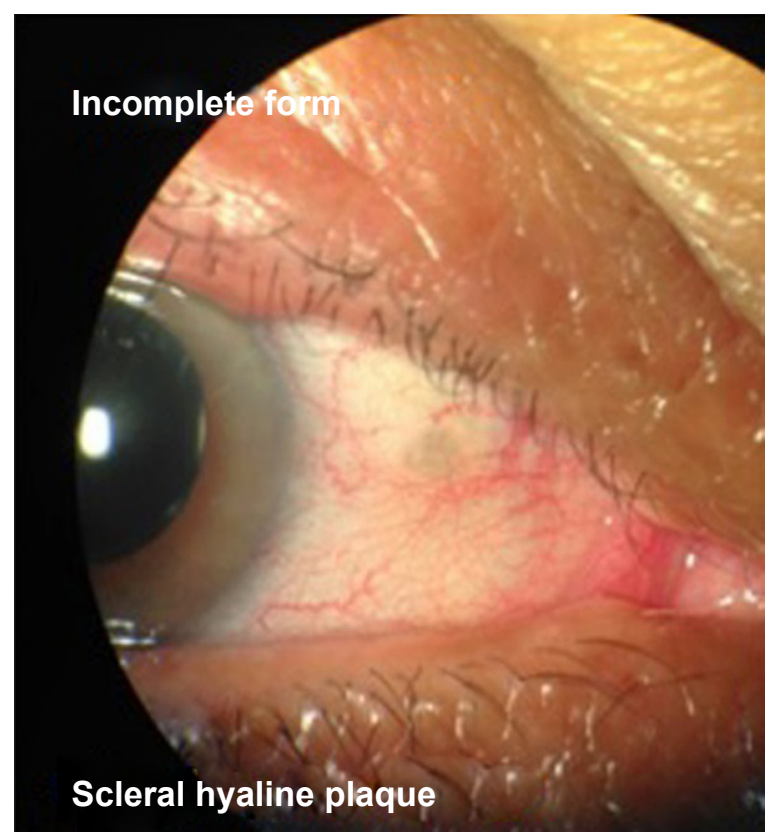

Figure 2 Biomicroscopy of anterior segment - scleral hyaline plaque - Incomplete form. 
size, position, and symmetry were taken into consideration. To improve the statistical analysis, the hyaline plaque variable was categorized as binary: absent (absence of hyaline plaque) or present (presence of complete or incomplete scleral hyaline plaque).

\section{Personal epidemiological and clinical data}

Variables related to factors possibly associated with scleral hyaline plaque were investigated. Such variables included the following: age (for the purpose of statistical analysis, this was categorized as $\leq 69$ years and $\geq 70$ years); sex (male, female); ethnicity (Latino, Caucasian, Afro-descendant, or other); iris color (light iris [blue and green], dark iris [brown]); moderate to high myopia (equal to or greater than four spherical diopters on refractive examination); age-related macular degeneration (AMD) (independent assessment of the wet and dry types); cataract (with visual acuity less than 20/40 on the Snellen chart); osteoporosis; degenerative arthritis; diabetes mellitus (both insulin- and non-insulin-dependent types); and systemic arterial hypertension. The variables moderate to high myopia, age-related cataract, AMD, diabetes mellitus, and systemic arterial hypertension were categorized as binary (present or absent), regardless of the stage of the disease progression. Interestingly, degenerative arthritis and osteoporosis were observed in their highest degree of the disease. Most patients with degenerative arthritis had done a knee prosthetic replacement surgery. Similarly, some patients with osteoporosis had undergone femur fracture repair surgery or treatment for scoliosis. These variables were also categorized as binary variables (absent or present).

\section{Statistical analysis}

To determine factors possibly associated with scleral hyaline plaques, statistical tests were used to analyze the correlation between the presence of plaques and the variables corresponding to the eye, systemic diseases, and to the participants' personal epidemiological data.

The $\chi^{2}$ test was used to determine the association between hyaline plaque and the variables sex, age range, ethnicity, AMD, cataract, moderate to high myopia, iris color, osteoporosis, degenerative arthritis, diabetes mellitus, and systemic arterial hypertension. Student's $t$-test was used in the analysis of the variable of age. A multivariate binary logistic regression analysis was performed to exclude the confounding effect of multiple factors because several of the analyzed variables were related to aging. Only the variables that exhibited statistical significance in the prior univariate analysis $(P<0.05)$ were included in the multivariate binary logistic regression analysis. Odds ratios, confidence intervals, and the significance were also calculated and included in the study results. The significance level was set to $5 \%$.

\section{Results \\ Scleral hyaline plaque}

Scleral hyaline plaques were present in 117 participants $(17.54 \%)$. In most cases, there were incomplete plaques (10.64\% of the total sample); the frequency of complete plaques was lower ( $6.9 \%$ of the total sample). No changes in the plaque size or depth were found during the follow-up period (15 months). The largest plaques measured $5.0 \times 2.0 \mathrm{~mm}$ (length $\times$ width) and were found in two participants at the age range of 80-89 years old. The smallest plaques measured $1.0 \times 1.0 \mathrm{~mm}$ and were found in 63 participants $(9.5 \%$ of the total sample). No evidence of plaque calcification was detected.

The results corresponding to the participants' personal epidemiological data and their correlation with the presence of hyaline plaque are described in Table 1.

\section{Sex}

The ratio of men to women was almost 1:1; a strong correlation was found between the presence of scleral hyaline plaque and female sex $(P=0.0001)$.

\section{Age and age range}

The participants' ages varied from 50 to 91 years old, with a mean \pm standard deviation of $68.37 \pm 9.33$ years respectively. The correlation between the presence of hyaline plaque and age range was found and exhibited statistical significance $(P=0.001)$. The presence of hyaline plaque predominated in the age range over 70 years. The participants with complete hyaline plaques were generally found in the higher age range (76.6 \pm 7.3 years), while the age range of the participants with incomplete hyaline plaques was $72.0 \pm 9.2$ years. In turn, the age range of the participants without hyaline plaques (67.7 \pm 9.1 years) was comparatively lower than that in the first two groups; this difference was statistically significant $(P=0.01)$.

\section{Iris color}

The correlation between the presence of scleral hyaline plaque and iris color were found not to exhibit statistical significance $(P=0.190)$.

\section{Ethnicity}

The correlation between the presence of scleral hyaline plaque and the variable ethnicity was found to exhibit statistical significance $(P=0.001)$. The presence of hyaline 
Table I Correlation between hyaline plaque (present/absent) and personal epidemiological data

\begin{tabular}{|c|c|c|c|c|c|c|}
\hline \multirow[t]{2}{*}{ Variables } & \multicolumn{6}{|c|}{ Scleral hyaline plaque } \\
\hline & $\begin{array}{l}\text { Complete form } \\
n=46\end{array}$ & $\begin{array}{l}\text { Incomplete form } \\
n=7 \mid\end{array}$ & $\begin{array}{l}\text { Present (complete }+ \\
\text { incomplete) } n=117\end{array}$ & $\begin{array}{l}\text { Absent } \\
n=550\end{array}$ & $\begin{array}{l}\text { Total } \\
\mathrm{n}=667\end{array}$ & $P$-value \\
\hline \multicolumn{7}{|l|}{ Sex, n (\%) } \\
\hline Male & $2(0.3)$ & $22(3.3)$ & $24(3.6)$ & $308(46.1)$ & $332(49.8)$ & 0.0001 \\
\hline Female & $44(6.6)$ & $49(7.3)$ & $93(13.9)$ & $242(36.2)$ & $335(50.2)$ & \\
\hline \multicolumn{7}{|l|}{ Age range, $n(\%)$} \\
\hline$\leq 69$ years & $9(0.5)$ & $31(4.6)$ & $40(5.9)$ & $334(50.2)$ & $374(56.1)$ & 0.001 \\
\hline$\geq 70$ years & $37(5.5)$ & $40(5.9)$ & 77 ( 11.5$)$ & $216(32.3)$ & $293(43.9)$ & \\
\hline \multicolumn{7}{|l|}{ Iris color, n (\%) } \\
\hline Light & $9(1.3)$ & $12(1.7)$ & $21(3.1)$ & $73(10.9)$ & $94(14.1)$ & 0.190 \\
\hline Dark & $37(5.6)$ & $59(8.8)$ & $96(14.4)$ & 477 (7I..5) & $573(85.9)$ & \\
\hline \multicolumn{7}{|l|}{ Ethnicity, n (\%) } \\
\hline Caucasian & $31(4.6)$ & $19(2.8)$ & $50(7.4)$ & $92(13.7)$ & $142(2 \mid .2)$ & \\
\hline Latino & $15(2.2)$ & $49(7.3)$ & $64(9.5)$ & $382(57.2)$ & $446(66.8)$ & 0.001 \\
\hline Afro-descendant & 0 & $3(0.4)$ & $3(0.4)$ & $36(5.4)$ & $39(5.8)$ & \\
\hline Other & 0 & 0 & 0 & $40(5.9)$ & $40(5.9)$ & \\
\hline
\end{tabular}

plaques was more frequent among Caucasians and less frequent among Afro-descendants.

\section{Eye diseases}

The results corresponding to the correlation between the presence of hyaline plaque and eye diseases, such as cataract, moderate to high myopia, and AMD, are shown in Table 2.

\section{Cataract}

Cataract was the eye disease that exhibited the highest prevalence in the present study ( $41.1 \%$ of the sample). The correlation between the presence of scleral hyaline plaque and cataract was statistically significant $(P=0.001)$.

\section{AMD}

AMD was detected in $14.39 \%$ of the participants; its correlation with the presence of scleral hyaline plaque was not statistically significant $(P=0.41)$.

\section{Moderate to high myopia}

Moderate to high myopia was detected in $10.20 \%$ of the sample, while myopic retinal degeneration with staphy-loma was found in only six participants. The correlation between the presence of scleral hyaline plaque and moderate to high myopia was statistically significant $(P=0.001)$.

\section{Systemic diseases}

The data on systemic diseases, including diabetes mellitus, arterial hypertension, degenerative arthritis, and osteoporosis, are shown in Table 3.

\section{Diabetes mellitus}

Diabetes mellitus was found in $7.2 \%$ of the sample and did not exhibit a statistically significant correlation with the presence of scleral hyaline plaque $(P=0.144)$. There were 35 participants with diabetic retinopathy.

Table 2 Correlation between hyaline plaque (present/absent) and eye diseases

\begin{tabular}{|c|c|c|c|c|c|c|}
\hline \multirow[t]{2}{*}{ Variables } & \multicolumn{6}{|c|}{ Scleral hyaline plaque } \\
\hline & $\begin{array}{l}\text { Complete form } \\
n=46\end{array}$ & $\begin{array}{l}\text { Incomplete form } \\
n=7 \text { I }\end{array}$ & $\begin{array}{l}\text { Present (complete }+ \\
\text { incomplete) } n=117\end{array}$ & $\begin{array}{l}\text { Absent } \\
n=550\end{array}$ & $\begin{array}{l}\text { Total } \\
\mathrm{n}=667\end{array}$ & $P$-value \\
\hline \multicolumn{7}{|c|}{ Cataract, n (\%) } \\
\hline Present & $27(4.0)$ & $5 \mathrm{I}(7.6)$ & $78(11.6)$ & $196(29.3)$ & $274(4 I . I)$ & 0.001 \\
\hline Absent & $19(2.8)$ & $20(3.0)$ & $39(5.8)$ & $354(53.1)$ & $393(58.9)$ & \\
\hline \multicolumn{7}{|c|}{ Moderate to high myopia, $\mathrm{n}(\%)$} \\
\hline Present & 0 & $25(3.8)$ & $25(3.8)$ & $43(6.4)$ & $68(10.2)$ & 0.001 \\
\hline Absent & $46(6.9)$ & $46(6.9)$ & $92(13.8)$ & $507(76.0)$ & $599(89.8)$ & \\
\hline \multicolumn{7}{|l|}{ AMD, n (\%) } \\
\hline Present & $8(1.4)$ & $18(2.7)$ & $26(3.9)$ & $70(10.4)$ & $96(14.4)$ & 0.41 \\
\hline Absent & $38(5.6)$ & $53(7.9)$ & 91 (13.6) & 480 (7I.9) & 57I (85.6) & \\
\hline
\end{tabular}

Abbreviation: AMD, age-related macular degeneration. 
Table 3 Correlation between hyaline plaque (present/absent) and systemic diseases

\begin{tabular}{|c|c|c|c|c|c|c|}
\hline \multirow[t]{2}{*}{ Variables } & \multicolumn{6}{|c|}{ Scleral hyaline plaque } \\
\hline & $\begin{array}{l}\text { Complete form } \\
n=46\end{array}$ & $\begin{array}{l}\text { Incomplete form } \\
n=7 \mid\end{array}$ & $\begin{array}{l}\text { Present (complete }+ \\
\text { incomplete) } n=117\end{array}$ & $\begin{array}{l}\text { Absent } \\
n=550\end{array}$ & $\begin{array}{l}\text { Total } \\
n=667\end{array}$ & $P$-value \\
\hline \multicolumn{7}{|c|}{ Diabetes mellitus, n (\%) } \\
\hline Present & $I(0.1)$ & $6(0.9)$ & $7(1.1)$ & $4 I(6.1)$ & $48(7.2)$ & 0.147 \\
\hline Absent & $45(6.7)$ & $65(9.7)$ & $110(16.4)$ & $509(76.3)$ & $619(92.8)$ & \\
\hline \multicolumn{7}{|c|}{ Systemic arterial hypertension, n (\%) } \\
\hline Present & $32(4.7)$ & $14(2.1)$ & $46(6.8)$ & 147 (22.0) & $193(28.9)$ & 0.01 \\
\hline Absent & $14(2.1)$ & $57(8.5)$ & $71(10.6)$ & $403(60.4)$ & $474(71.0)$ & \\
\hline \multicolumn{7}{|c|}{ Degenerative arthritis, $\mathrm{n}(\%)$} \\
\hline Present & $33(4.9)$ & $14(2.1)$ & $47(7.0)$ & $21(3.1)$ & $68(10.2)$ & 0.0001 \\
\hline Absent & $13(1.9)$ & $57(8.5)$ & $70(10.4)$ & $529(79.3)$ & $599(89.8)$ & \\
\hline \multicolumn{7}{|c|}{ Osteoporosis, n (\%) } \\
\hline Present & $23(3.4)$ & $27(4.0)$ & $50(7.4)$ & $102(15.3)$ & $152(22.8)$ & 0.001 \\
\hline Absent & $23(3.4)$ & $44(6.6)$ & $67(10.0)$ & $448(67.1)$ & $515(77.2)$ & \\
\hline
\end{tabular}

\section{Systemic arterial hypertension}

Systemic arterial hypertension was found in $28.93 \%$ of the sample and exhibited a statistically significant correlation with the presence of scleral hyaline plaque $(P=0.01)$. There were no cases of hypertensive retinopathy in the sample.

\section{Degenerative arthritis}

Degenerative arthritis was found in $10.2 \%$ of the sample and exhibited a statistically significant correlation with the presence of scleral hyaline plaque $(P=0.0001)$.

\section{Osteoporosis}

Osteoporosis was found in $22.8 \%$ of the sample and exhibited a statistically significant correlation with the presence of scleral hyaline plaque $(P=0.01)$.

\section{Multivariate logistic regression analysis}

The results of the multivariate logistic regression analysis are described in Table 4. The following variables were found to exhibit a significant correlation with the presence of scleral hyaline plaque: female sex, age range over 70 years, moderate to high myopia, and degenerative arthritis. Among these,

Table 4 Multivariate logistic regression analysis of factors associated with scleral hyaline plaque

\begin{tabular}{llll}
\hline & P-value & OR & Cl \\
\hline Sex (female) & $0.000 \mathrm{I}$ & 5.487 & $2.93-10.24$ \\
Age range ( $\geq 70$ years) & 0.05 & 1.783 & $1.23-2.93$ \\
Ethnicity (Caucasian) & 0.25 & 1.345 & $0.47-2.19$ \\
High myopia & 0.01 & 2.223 & $1.89-3.01$ \\
Cataract & 0.10 & 0.945 & $0.64-1.23$ \\
Systemic arterial hypertension & 0.57 & 0.363 & $0.11-0.93$ \\
Degenerative arthritis & 0.001 & 3.870 & $1.13-6.23$ \\
Osteoporosis & 0.20 & 1.647 & $0.56-2.48$ \\
\hline
\end{tabular}

Abbreviations: $\mathrm{Cl}$, confidence interval; $\mathrm{OR}$, odds ratio. female sex and degenerative arthritis exhibited the strongest correlations with the presence of hyaline plaque. The variables ethnicity, cataract, systemic arterial hypertension, and osteoporosis did not exhibit a significant correlation with the presence of hyaline plaque, after being submitted to the multivariate analysis.

\section{Discussion}

Scleral plaques result from hyaline collagen degeneration. It is characterized by the presence of a discrete grayish and depressed areas in front of the insertion of the medial and lateral rectus muscles. ${ }^{9-12}$ The studies on scleral hyaline plaque that were published in the medical literature from the beginning of the 20th century were restricted to case reports or small case series. ${ }^{2-4}$ Garner and Klintworth report that in 1933, Pillat published the first thorough description of this condition, calling it a senile scleral hyaline plaque. ${ }^{12}$ Despite this, the pathophysiology of hyaline plaque was poorly understood during the middle of the 20th century. Its etiology, whether degenerative or inflammatory, could not be established. ${ }^{9}$

Large epidemiological studies were conducted, by Norn, only in the 1970s and 1980s..6, ${ }^{4-13}$ Norn observed that the size of scleral hyaline plaques might increase over time and suggested the term "preplaque" for the initial stages of lesions. ${ }^{13}$ The prevalence of scleral hyaline plaque found in the present study (17.54\%) was higher than in the previous reports (ranging from $1 \%$ to $25 \%$ ) in the literature, whereas the prevalence of the complete type was lower $(6.9 \%){ }^{4}$ However, the largest epidemiological studies reporting prevalence rates did not apply any inclusion or exclusion criteria. Further, in recent times, there has been an increase in the size and longevity of the population of older adults worldwide. ${ }^{5,6,14}$ According to Roper ${ }^{3}$ and Graves, ${ }^{15}$ scleral 
hyaline plaque would be much more frequently diagnosed if doctors were to look more carefully for it in the course of ophthalmologic examinations. The authors of the current work agree with that statement.

Two hypotheses have been proposed for the cause of scleral hyaline plaque: mechanical stress and actinic damage. In support of the first hypothesis is the fact that plaques closer to the medial rectus muscle are often larger compared with plaques next to the lateral rectus muscle of the same eye. ${ }^{4,5,12}$ This relationship was also evident in the present study. However, the higher frequency of hyaline plaques among Caucasian participants and the lower frequency among Afro-descendants in the present study supports the hypothesis of actinic damage. In this regard, it is worth noting that the ethnic status of the Brazilian population is difficult to classify as a result of the considerable miscegenation that has taken place in the country.

In regard to the variables age and age range, Norn found hyaline plaques much more frequently among older adults. ${ }^{13}$ In the present study, the frequency of scleral plaques increased simultaneously with age. The presence of scleral plaques was also significantly associated with the female sex. The fact that the ratio of men to women was almost 1:1 makes this finding even more relevant. Norn reported a rate of $12 \%$ among women and 7\% among men; however, the female predominance was not statistically significant. ${ }^{4}$ The higher prevalence of scleral plaques among women might be associated with hormones at the onset of this condition, particularly during menopause. ${ }^{16,17}$ With respect to eye diseases and their influence on hyaline plaque, Norn investigated its relationship with arcus senilis, cataract, and corneal thickness but did not find any statistically significant association. ${ }^{4,5}$ In the present study, the authors investigated the association of hyaline plaque with cataract, moderate to high myopia, and AMD. Although the variable cataract exhibited a statistically significant association with the presence of hyaline plaque, this factor lost significance on multivariate analysis. In addition, moderate to high myopia exhibited a statistically significant association with the presence of hyaline plaque. This present study was the first to investigate that association.

Other authors have analyzed the relationship between hyaline plaque, scleral rigidity, and low corneal thickness but did not obtain significant results. ${ }^{18,19}$ In the present study, no association was found between hyaline plaque and diabetes mellitus. Systemic arterial hypertension and osteoporosis exhibited a statistically significant association on univariate analysis, but these associations lost significance on multivariate analysis. Different from the cases above, degenerative arthritis exhibited a strong correlation with the presence of hyaline plaques. No other mention of this finding could be found in the literature. The pathophysiology of degenerative arthritis, which involves collagen alterations, might have similarities with scleral degeneration. Indeed, both conditions are characterized by alterations in the collagen fibers, which, in the latter case, may result from mechanical stress close to the insertion of the extraocular rectus muscles. ${ }^{11,12,20}$

\section{Conclusion}

To conclude this present study, the authors investigated factors that could potentially be associated with the presence of scleral hyaline plaque. The authors concluded that female sex, degenerative arthritis, age range over 70 years, and moderate to high myopia were associated with the presence of hyaline plaque. The authors expect the increase of knowledge on this variety of scleral degeneration because its frequency will most likely increase as a result of the greater longevity and aging of the world's population. Further, the increase of procedures involving the scleral area in which hyaline plaques appear (vitreoretinal surgery) might lead to a greater influence of this variety of degenerative disorder on scleral wound healing. ${ }^{21}$

\section{Acknowledgment}

The authors thank Professor Mauricio Pereira for the scleral plaque photographs.

\section{Disclosure}

The authors report no conflicts of interest in this work.

\section{References}

1. Boshoff PH. Hyaline scleral plaques. Arch Ophthalmol. 1942;28(3): 503-506.

2. Cogan DG, Kuwabara T. Focal senile translucency of the sclera. Arch Ophthalmol. 1959;62:604-610.

3. Roper KL. Senile hyaline scleral plaque. Arch Ophthal. 1945;34: 283-291.

4. Norn MS. Scleral plaques. I. Incidence and morphology. Acta Ophthalmol (Copenh). 1974;52(1):96-106.

5. Norn MS. Episcleral lipid deposits and scleral plaques in Japan (Kyoto). Acta Ophthalmol (Copenh). 1983;61(6):685-690.

6. Norn MS. Scleral plaques. II. Follow-up, cause. Acta Ophthalmol (Copenh). 1974;52(4):512-520.

7. Moseley I. Spots before the eyes: a prevalence and clinicoradiological study of senile scleral plaques. Clin Radiol. 2000;55(3):198-206.

8. Scroggs MW, Klintworth GK. Senile scleral plaques: a histopathologic study using energy-dispersive x-ray microanalysis. Hum Pathol. 1991;22(6):557-562.

9. Manschot WA. Senile scleral plaques and senile scleromalacia. $\mathrm{Br}$ J Ophthalmol. 1978;62(6):376-380.

10. Neogi T, Zhang Y. Epidemiology of osteoarthritis. Rheum Dis Clin North Am. 2013;39(1):1-19.

11. Guilak F. Biomechanical factors in osteoarthritis. Best Pract Res Clin Rheumatol. 2011;25(6):815-823. 
12. Garner A, Klintworth GK. Pathobiology of Ocular Disease. A Dynamic Approach. New York, NY: Dekker; 1982.

13. Norn MS. Scleral preplaques and plaques in Eskimos. The incidence in West Greenland Eskimos compared with that in Copenhagen Caucasians. Acta Ophthalmol (Copenh). 1975;53(6):894-900.

14. Who.int [homepage on the Intranet]. WHO Study on global AGEing and adult health (SAGE). World Health Organization; 2015. Available from: http://www.who.int/healthinfo/systems/sage/en. Accessed June 12, 2014.

15. Graves B. Scleral plaques. Br J Ophthalmol. 1952;36(5):272-273.

16. Wagner H, Fink BA, Zadnik K. Sex- and gender-based differences in healthy and diseased eyes. Optometry. 2008;79(11):636-652.

17. Gupta PD, Johar K Sr, Nagpal K, Vasavada AR. Sex hormone receptors in the human eye. Surv Ophthalmol. 2005;50(3):274-284.
18. Jonas JB, Xu L. Histological changes of high axial myopia. Eye (Lond). 2014;28(2):113-117.

19. McBrien NA, Cornell LM, Gentle A. Structural and ultrastructural changes to the sclera in a mammalian model of high myopia. Invest Ophthalmol Vis Sci. 2001;42(10):2179-2187.

20. Seko Y, Azuma N, Takahashi Y, et al. Human sclera maintains common characteristics with cartilage throughout evolution. PLoS One. 2008;3(11):e3709.

21. Pavlin CJ, Easterbrook M, Hurwitz JJ, Harasiewicz K, Eng P, Foster FS. Ultrasound biomicroscopy in the assessment of anterior scleral disease. Am J Ophthalmol. 1993;116(5):628-635.
Clinical Ophthalmology

\section{Publish your work in this journal}

Clinical Ophthalmology is an international, peer-reviewed journal covering all subspecialties within ophthalmology. Key topics include: Optometry; Visual science; Pharmacology and drug therapy in eye diseases; Basic Sciences; Primary and Secondary eye care; Patient Safety and Quality of Care Improvements. This journal is indexed on

Submit your manuscript here: http://www.dovepress.com/clinical-ophthalmology-journal

\section{Dovepress}

PubMed Central and CAS, and is the official journal of The Society of Clinical Ophthalmology (SCO). The manuscript management system is completely online and includes a very quick and fair peer-review system, which is all easy to use. Visit http://www.dovepress.com/ testimonials.php to read real quotes from published authors. 